\title{
Expression and adaptive regulation of amino acid transport system $A$ in a placental cell line under amino acid restriction
}

\author{
H N Jones ${ }^{1,2,3}$, C J Ashworth ${ }^{2}$, K R Page $^{3}$ and H J McArdle ${ }^{1}$ \\ ${ }^{1}$ Maternal-Fetal Physiology, Rowett Research Institute, Greenburn Road, Bucksburn, Aberdeen AB21 9SB, UK, \\ ${ }^{2}$ Animal Breeding and Development, Scottish Agricultural College, Aberdeen AB21 9YA, UK and ${ }^{3}$ College of Life \\ Science and Medicine, University of Aberdeen, Aberdeen AB25 2ZD, UK
}

Correspondence should be addressed to H J McArdle; Email: H.McArdle@rowett.ac.uk

\begin{abstract}
Trans-placental transport of amino acids is vital for the developing fetus. Using the BeWo cell line as a placental model, we investigated the effect of restricting amino acid availability on amino acid transport system type A. BeWo cells were cultured either in amino acid-depleted (without non-essential amino acids) or control media for 1, 3, 5 or $6 \mathrm{~h}$. System A function was analysed using $\alpha$ (methyl-amino)isobutyric acid (MeAIB) transcellular transport studies. Transporter (sodium coupled neutral amino acid transporter (SNAT1/2)) expression was analysed at mRNA and protein level by Northern and Western blotting respectively. Localisation was carried out using immunocytochemistry. MeAIB transcellular transport was significantly $(P<0.05)$ increased by incubation of the cells in amino acid-depleted medium for $\mathbf{1} \mathbf{h}$, and longer incubation times caused further increases in the rate of transfer. However, the initial response was not accompanied by an increase in SNAT2 mRNA; this occurred only after $3 \mathrm{~h}$ and further increased for the rest of the 6 -h incubation. Similarly, it took several hours for a significant increase in SNAT2 protein expression. In contrast, relocalisation of existing SNAT2 transporters occurred within 30 min of amino acid restriction and continued throughout the 6-h incubation. When the cells were incubated in medium with even lower amino acid levels (without non-essential plus $0.5 \times$ essential amino acids), SNAT2 mRNA levels showed further significant $(P<0.0001)$ up-regulation. However, incubation of cells in depleted medium for $6 \mathrm{~h}$ caused a significant $(P=0.014)$ decrease in the expression of SNAT1 mRNA. System L type amino acid transporter 2 (LAT2) expression was not changed by amino acid restriction, indicating that the responses seen in the system A transporters were not a general cell response. These data have shown that placental cells adapt in vitro to nutritional stress and have identified the physiological, biochemical and genomic mechanisms involved.
\end{abstract}

Reproduction (2006) 131 951-960

\section{Introduction}

Trans-placental transport of amino acids is vital for the developing fetus. Transfer can be considered as occurring in three stages: uptake, movement across the cell layer and efflux into the fetal circulation. It has been shown that expression of placental iron (Fe) transport proteins increases in Fe deficiency (Gambling et al. 2001). Both uptake and efflux proteins are up-regulated, while storage protein expression is reduced. These data correlate with increased partitioning of Fe to the fetus at the expense of maternal stores (Gambling et al. 2001).

There are few, if any, publications examining amino acid status and transfer of amino acids across a placental model enabling elucidation of the underlying mechanisms of regulation, although there are studies examining the effect of availability on uptake into the placental cell (e.g. Smith \& Depper 1974). Trans-placental transfer of $\alpha$-aminoisobytyric acid (AIB), leucine and lysine has been demonstrated in human (Schneider et al. 1987) and guinea pig (Carstensen \& Leichtweiss 1986, Wheeler \& Yudilevich 1989) placentas. In the human, net transfer from mother to fetus is achieved by rapid uptake from the maternal circulation followed by transfer to the fetal circulation (Schneider et al. 1987). In the guinea pig, sodiumdependent transfer was predominantly located on the maternal face of the placenta, again giving a net drive from mother to fetus (Carstensen \& Leichtweiss 1986, Wheeler \& Yudilevich 1989). However, none of these studies identified the effects of nutrient availability on placental amino acid transfer or on the regulation of the transport systems at mRNA or protein level.

Amino acid transport system type A ('system A') mediates the sodium-dependent uptake of amino acids with 
small side chains such as alanine, serine, proline and glutamine. System A was functionally identified by the transport of $\mathrm{N}$-alkylated substrates, for example $\alpha$-(methylamino)isobutyric acid (MeAIB), and activity was first shown in the human placenta by Smith et al. (1973). Tarnuzzer et al. (1990) demonstrated that microinjection of placental mRNA into Xenopus oocytes conferred system A transport activity identified by MeAIB uptake studies. Three isoforms of system A have recently been identified. Sodium coupled neutral amino acid transporter (SNAT)1 (amino acid transport system type A1, ATA1; solute carrier $38 \mathrm{~A} 1, \mathrm{SLC} 38 \mathrm{~A} 1$ ) is expressed highly in the human heart and placenta (Wang et al. 2000). SNAT2 (ATA2, SLC38A2) is expressed ubiquitously in humans (Hatanaka et al. 2000, Sugawara et al. 2000a). SNAT1 and SNAT2 are functionally similar and the genes for these transporters are encoded in close proximity to one another on chromosome 12 (Wang et al. 2000). SNAT4 (ATA3, SCL38A3) was identified primarily by sequence similarity. It is expressed primarily in liver and skeletal muscle (Sugawara et al. 2000b) and has recently been shown to be present in the syncytiotrophoblast of the placenta (Desforges et al. 2005). It is not expressed in trophoblast cell lines such as BeWo (Desforges et al. 2005). Whether it is primarily involved in transport of substrates for system A is not clear, since it may also transport branched-chain amino acids (Sugawara et al. 2000b).

Amino acid uptake by system $\mathrm{A}$ is highly regulated in many cell types. Its effectors include $\mathrm{pH}$, cell volume (Ruiz-Montasell et al. 1994) and a variety of hormones such as insulin (McDowell et al. 1998), glucagon (Yao et al. 2000) and insulin-like growth factor-I (Karl 1995). Amino acid availability has also been shown to regulate system A function in several cell types including hepatocytes (Bracy et al. 1986) and placental fragments (Smith \& Depper 1974), and SNAT2 undergoes the process of 'adaptive regulation' in C6 glioma cells (Ling et al. 2001), L6 myotubes and adipocytes (Hyde et al. 2001) when incubated in amino acid-free medium. This response, which mirrors the effect on actual transport of system A substrates, involves two phases. The acute phase involves recruitment of preformed transporters from intracellular stores to the cell membrane. The chronic phase results in an increase in both mRNA and protein synthesis for new transporter formation. In cultured human fibroblasts, amino acid starvation triggers a marked increase in SNAT2 mRNA abundance which proceeds for at least $18 \mathrm{~h}$ (Franchi-Gazzola et al. 1999). SNAT2 mRNA levels decrease after amino acid re-feeding of previously starved cells, and replacing all system A substrates has a greater effect than replacing just one. It has not yet been established if SNAT1 expression at the molecular level contributes to the adaptive regulation of system $\mathrm{A}$ amino acid transport under starvation conditions.

In the placenta, there is very limited information on whether such mechanisms operate. Smith \& Depper (1974) suggested that system $A$ in the placenta may be regulated by substrate but these data did not examine protein or gene expression. The transporters for placental taurine uptake show a substrate-specific adaptive response involving both transcriptional and post-transcriptional events in taurinedeprived JAR cells (Jayanthi et al. 1995). More recently, Novak \& Matthews (2003) identified that the system $X_{\mathrm{AG}}^{-}$ proteins, EAAC1, GLAST1 and GLT1, were involved in increased glutamate uptake into rat choriocarcinoma cells (Rcho-1) when cells are exposed to amino acid deprivation. However, there are no studies that have examined the effect of nutrient deprivation on flux across the whole cell layer, as opposed simply to uptake at the microvillar surface. This, of course, is of particular relevance when considering amino acid supply to the developing fetus. In this study, therefore, we have examined the effect of substrate limitation on the expression of SNAT1 and 2 at transport, mRNA and protein levels. Further, we also measured the effect of the treatment on the expression of system $\mathrm{L}$ type amino acid transporter 2 (LAT2) (solute carrier 7A8, SLC7A8 (Pineda et al. 1999)), to determine whether the changes are specific to the transporters of system A or reflect a generalised stress response of the placental cells.

Since there is no primary trophoblast model which forms a transporting monolayer (Vardhana \& Illsley 2002) we have used the BeWo choriocarcinoma cell line grown on permeable supports to study the transcellular transfer of MeAIB. BeWo cells form a single layer on permeable supports with morphological and functional polarity (Liu et al. 1997). They have previously been used in monolayer culture to study the uptake of lysine (Way et al. 1998) and amino acid transport system L (Ritchie \& Taylor 2001, Okamoto et al. 2002) and to characterise alanine uptake (Moe et al. 1994). On permeable supports they have been used to study the transepithelial transport of folic acid (Takahashi et al. 2001), glucose (Vardhana \& Illsley 2002) and valproic acid (Utoguchi \& Audus 2000). However, to date there are no studies of transcellular transfer, or its regulation, of amino acids. This study therefore combined molecular and physiological techniques to examine the effect of nutrient restriction on trophoblast cell transfer of a system $A$ substrate and on the mechanisms that underpin delivery to the growing fetus.

\section{Materials and Methods \\ Cell culture}

The b30 clone of the BeWo choriocarcinoma cell line was obtained from Dr A L Schwartz (Wice et al. 1990). The cells were routinely maintained in $80 \mathrm{~cm}^{2}$ flasks at $37^{\circ} \mathrm{C}$ under $5 \% \mathrm{CO}_{2}$ and cultured in Dulbecco's modified Eagles' medium (DMEM) Glutamax 1 supplemented with $10 \%$ fetal calf serum and $2 \%$ penicillin/streptomycin (Invitrogen, Paisley, Strathclyde, UK). The medium was changed every 2 days and cells were subcultured every 7 days. All cells used were between passages 8 and 15. For transport studies, cell monolayers were prepared by seeding 
$25 \mathrm{~mm}$ tissue culture inserts (non-collagen coated) (Nunc, Paisley, Strathclyde, UK) at a high density $\left(5 \times 10^{5}\right)$. Cell monolayers were maintained at $37^{\circ} \mathrm{C}$ under $5 \% \mathrm{CO}_{2}$. The tightness of the monolayer was assessed by the determination of transepithelial resistance over a 7-day period using a hand-held EVOM Epithelial Voltohmeter and STX-3 electrodes (World Precision Instruments, Stevenage, Hertfordshire, UK). The longer electrode was placed into the cell culture well until it just reached the bottom and the shorter electrode was submersed in the medium covering the cell culture insert but not touching it. Transepithelial electrical resistance (TEER) measurements were also performed on unseeded control inserts.

\section{Amino acid restriction}

Cells at $80 \%$ confluency in flasks or confluent monolayers on inserts were cultured at $37^{\circ} \mathrm{C}$ for $1,3,5$ or $6 \mathrm{~h}$ in either control DMEM Glutamax 1 or balanced salt solution (BSS: $136 \mathrm{mM} \mathrm{NaCl}, 5 \mathrm{mM} \mathrm{KCl}, 1 \mathrm{mM} \mathrm{MgCl} 2,1 \mathrm{mM} \mathrm{CaCl} 2$ and $18 \mathrm{mM}$ Hepes, $\mathrm{pH} 7.4$ at $37^{\circ} \mathrm{C}$ ) supplemented with $1 \times$ minimum essential medium (MEM) essential amino acid solution (Invitrogen) to give the equivalent concentration of essential amino acids as in the control medium but without any non-essential amino acids (RM1). Other flasks were cultured for $6 \mathrm{~h}$ in BSS supplemented with $0.5 \times$ MEM essential amino acids to produce essential as well as non-essential amino acid deprivation (RM2).

\section{cDNA probes and antibodies}

Human specific SNAT1 and LAT2 probes $2964 \mathrm{bp}$ and $1430 \mathrm{bp}$ were prepared from full length I.M.A.G.E clones ID 3871101 and 322502 respectively. I.M.A.G.E. clones were obtained from the Human Genome Mapping Project resource centre (Cambridge, Cambs, UK; Lennon et al. 1996). A human specific SNAT2 probe $328 \mathrm{bp}$ was prepared by reverse transcription-PCR using standard protocols and primers designed from human sequences. The sense and anti-sense primers correspond to 2438-2457 and 2746-2766 of human SNAT2 (Genbank accession number AF259799). A probe against 18S RNA was used to normalise the mRNA expression data. All cDNA probes were sequenced and used in BLASTn (basic local alignment search tool of nucleotide sequences, http://www.ncbi.nih.gov/BLAST) searches to confirm the specificity of the probes. Antibodies prepared against peptide sequence-specific human SNAT2 (ESNLGKKKYETEFHPG) were obtained from PRIMM (Milan, Italy). Mouse anti-human $\beta$-actin (Sigma) antibody was used to normalise protein expression data.

\section{MeAIB transcellular transport}

$\alpha-\left[1-{ }^{14} \mathrm{C}\right]$ methylaminoisobutyric acid and D-[1- $\left.{ }^{3} \mathrm{H}(\mathrm{N})\right]-$ mannitol were obtained from Perkin Elmer (Boston, MA, USA). Cell monolayers were washed three times in BSS $\left(\mathrm{pH} 7.4\right.$ at $\left.37^{\circ} \mathrm{C}\right)$ and placed in fresh six-well plates with
$2 \mathrm{ml}$ BSS. Radiolabelled MeAIB $(0.2 \mu \mathrm{Ci})$, with MeAIB added to give a final concentration of $10 \mu \mathrm{M}$ to allow tranporter saturation and mannitol $(0.2 \mu \mathrm{Ci})$ were added to the apical side in $1 \mathrm{ml}$ serum-free medium. Samples $(100 \mu \mathrm{l})$ were taken from the basolateral side at 1, 3, 5, 10 and $20 \mathrm{~min}$ and replaced with fresh medium. Basolateral radiolabel was determined by scintillation counting. Mannitol was included in the experiments to assess the passive component of MeAIB transepithelial transport. The ratio of apical $\left[{ }^{3} \mathrm{H}\right]$ mannitol to $\left[{ }^{14} \mathrm{C}\right] \mathrm{MeAIB}$ was calculated. This ratio was applied to the basolateral $\left[{ }^{3} \mathrm{H}\right]$ mannitol counts and the resulting figure (representing passive $\left[{ }^{14} \mathrm{C}\right] \mathrm{MeAIB}$ transfer) was deducted from basolateral $\left[{ }^{14} \mathrm{C}\right] \mathrm{MeAIB}$ counts. To calculate rates of transfer, we derived the slope of the line from the data at 1, 3, 5, 10 and $20 \mathrm{~min}$. The fluxes which have been attributed to the monolayer did not take into account the contribution of the inserts; it was assumed that this remained constant throughout the experimental conditions employed.

\section{Western blotting}

BeWo cells were washed three times in ice-cold BSS at $\mathrm{pH}$ 7.4. Cells were homogenised and sonicated. Total protein $(30 \mu \mathrm{g})$ was separated on a $7.5 \%$ Tris-glycine gel and transferred to Hybond-ECL nitrocellulose membrane (Amersham Biosciences, Little Chalfont, Bucks, UK) by electrophoresis. Membranes were incubated with the appropriate primary antibody $(1: 500)$ overnight at $4{ }^{\circ} \mathrm{C}$ and an HRP-anti-rabbit IgG antibody (1:5000; Sigma) for $2 \mathrm{~h}$ at room temperature. Protein bands were visualised using Super Signal West Pico Chemiluminescent substrate (Pierce, Rockford, IL, USA). Protein expression was quantified using densitometry normalised against $\beta$-actin for loading controls and internal controls for blot comparison.

\section{Immunocytochemistry}

Immunofluorescence staining was performed on BeWo cells on glass coverslips following exposure to either control or RM1 medium for $0.5,2,4$ or $6 \mathrm{~h}$. Cells were also exposed to RM1 for $4 \mathrm{~h}$ and then returned to control medium for a further $2 \mathrm{~h}$ or left in RM1 prior to immunocytochemistry. Cells were fixed in frozen methanol for $5 \mathrm{~min}$. To quench autofluorescence, the coverslips were incubated in $50 \mathrm{mM} \mathrm{NH}_{4} \mathrm{Cl}$ for $10 \mathrm{~min}$ at room temperature. To prevent non-specific binding, coverslips were incubated with $0.2 \%$ fish skin gelatin (FSG)/PBS for $5 \mathrm{~min}$ at room temperature. Primary antibody (1:50) was applied to coverslips in $0.2 \%$ FSG/PBS and allowed to bind overnight at $4{ }^{\circ} \mathrm{C}$ in a humidified atmosphere. Following rinses in $0.2 \%$ FSG/PBS, the anti-rabbit FITC conjugated antibody (1:100; Vector Laboratories Inc, Burlinghame, CA, USA) was applied to the coverslips for $1 \mathrm{~h}$ at room temperature in a humidified atmosphere. The coverslips were rinsed in PBS and deionised water and mounted in Vectashield mounting medium (Vector Laboratories). Cells 
were observed and images captured using an Axioscop microscope $(100 \times)$, Axiocam and AxioVision software (Carl Zeiss Vision GmbH, Hamburg, Germany). Antibody specificity was confirmed by preincubation of the SNAT2 antibody with its antigenic peptide and omittance of the primary antibody during immunocytochemistry.

\section{Northern blotting}

BeWo RNA was isolated using TRI reagent (Helena Biosciences, Sunderland, Tyne and Wear, UK). Total RNA $(10 \mu \mathrm{g})$ was separated on a $1 \%$ (formaldehyde) agarose gel, transferred to a nylon membrane (Amersham International) by electrophoresis at $100 \mathrm{~mA}$ at $4{ }^{\circ} \mathrm{C}$ overnight and cross-linked using a u.v. cross-linker (Ultra-violet Products, Upland, CA, USA). The cDNA probe was labelled with $\left[\alpha-{ }^{32} \mathrm{P}\right] \mathrm{dCTP}$ Ready-to-go labelling beads (Amersham International). Hybridisations were performed overnight at $42{ }^{\circ} \mathrm{C}$. mRNA was quantified by measuring the amount of radioactivity hybridising to the bands on the Northern blot using a wire proportional counter (Packard instant imager; Packard Bioscience Ltd, Pangbourne, Berks, UK).

\section{Statistical analysis}

Statistical significance was assessed at the 0.05 level using the Student's $t$-test and one-way ANOVA with Tukey's multiple comparison tests.

\section{Results}

\section{Trans-epithelial electrical resistance across BeWo monolayers}

TEER measurements were recorded across BeWo monolayers from seeding. There was no significant increase over basal values (unseeded inserts: mean \pm S.E.M. of six passages, $126 \pm 19.5 \Omega \mathrm{cm}^{2}$ ) until 4 days after seeding. Thereafter, TEER increased to a maximum (mean \pm S.E.M. of eight passages, $220 \pm 15.5 \Omega \mathrm{cm}^{2}$ ) at 6 days. Exposure of the monolayers to the different media did not alter the TEER measurements.

\section{[3 H]mannitol transepithelial transport}

Passive diffusion across the BeWo monolayers was assessed by measuring the amount of $\left[{ }^{3} \mathrm{H}\right]$ mannitol in the basal chamber over a 20-min time-period. The transfer rates were calculated to investigate if exposure to amino acid restriction affected the permeability of the monolayer. There was no change in mannitol transfer rate following incubation in RM1 compared with control medium (Table 1).

\section{$\left[{ }^{14} \mathrm{C}\right] \mathrm{Me} A I B$ transcellular transport}

The rate of flux across the cell layer was measured by counting $\left[{ }^{14} \mathrm{C}\right] \mathrm{MeAIB}$ in the basal chamber. Figure $1 \mathrm{~A}$
Table 1 Passive diffusion of mannitol across BeWo monolayers exposed to control and amino acid-restricted media.

\begin{tabular}{lc}
\hline Medium & $\begin{array}{c}\text { Mannitol transfer rates } \\
\left(\text { pmol/min per } \mathrm{cm}^{2} \pm \text { S.E.M. }\right)\end{array}$ \\
\hline Control $(1,3,5$ and $6 \mathrm{~h})$ & $0.364 \pm 0.164$ \\
RM1 $(1 \mathrm{~h})$ & $0.324 \pm 0.135$ \\
RM1 (3 h) & $0.298 \pm 0.155$ \\
RM1 (5 h) & $0.340 \pm 0.097$ \\
RM1 (6 h) & $0.282 \pm 0.178$ \\
\hline
\end{tabular}

shows levels of $\left[{ }^{14} \mathrm{C}\right] \mathrm{MeAIB}$ in the basolateral chamber at increasing times following addition of label to the apical chamber (time 0). Uptake took about 1 min for the transfer of the labelled amino acid to achieve steady state; that is, for the rate to become linear. Between 0 and $1 \mathrm{~min}$, as the intracellular pool(s) filled and the uptake and efflux steps moved towards steady state, the rate was lower than when the steady state was attained. Thus, in the first minute, the transfer rate was measured as $0.027 \pm 0.019 \mathrm{nmol} / \mathrm{min}$ per $\mathrm{cm}^{2}$. From 1 to $20 \mathrm{~min}$, the rate became linear, as the system was then at an apparent steady state with a flux rate of $0.092 \pm 0.016 \mathrm{nmol} / \mathrm{min}$ per $\mathrm{cm}^{2}$ (Fig. 1A). The concentration of MeAIB on the apical membrane was $10 \mu \mathrm{M}$. On the basolateral side, it never exceeded $1 \mathrm{pM}$, so that the flux was considered as essentially uni-directional. This was further supported by the fact that the measured transfer rate remained linear over the timeperiod measured. In this graph (Fig. 1A), the effect of starvation is shown at 1 and $6 \mathrm{~h}$ after addition of medium. Times 3 and $5 \mathrm{~h}$ are omitted for the sake of clarity.

The effect of starvation on transepithelial movement was measured at different times after the addition of medium RM1. At each time-point, the medium was removed, the cells were washed and the transfer was measured by incubating in BSS with $\left[{ }^{14} \mathrm{C}\right] \mathrm{MeAIB}$. As described in the previous paragraph, the true flux was measured between 1 and $20 \mathrm{~min}$. Figure $1 \mathrm{~B}$ shows these data. At $1 \mathrm{~h}$, there was a significant increase in the rate of transfer and by $3 \mathrm{~h}$ of incubation the effect became highly significant, and it continued to increase for at least $6 \mathrm{~h}$ after addition of RM1 (Fig. 1B).

\section{Effect of amino acid restriction on mRNA expression}

As described by Hatanaka et al. (2001), there were two distinct mRNA species specific for SNAT1 $(9 \mathrm{~kb}$ and $2.8 \mathrm{~kb})$. Following incubation of the BeWo cell line in RM1 and RM2 for $6 \mathrm{~h}$, the $2.8 \mathrm{~kb}$ SNAT1 species was not regulated by the availability of essential or non-essential amino acids. In contrast, the $9 \mathrm{~kb}$ SNAT1 species showed a significant $(P<0.001$, one-way ANOVA, $n=9)$ decrease in expression as a consequence of incubation for $6 \mathrm{~h}$ in RM1 (Fig. 2). This effect was reversed when the cells were incubated for $6 \mathrm{~h}$ in RM2, with expression levels remaining at control values. Incubation of the BeWo cell line in RM1 for $1 \mathrm{~h}$ did not cause an increase in SNAT2 mRNA. However, incubation for $3 \mathrm{~h}$ caused a significant $(P<0.05, n=6)$ 1.5-fold increase in SNAT2 mRNA expression compared 

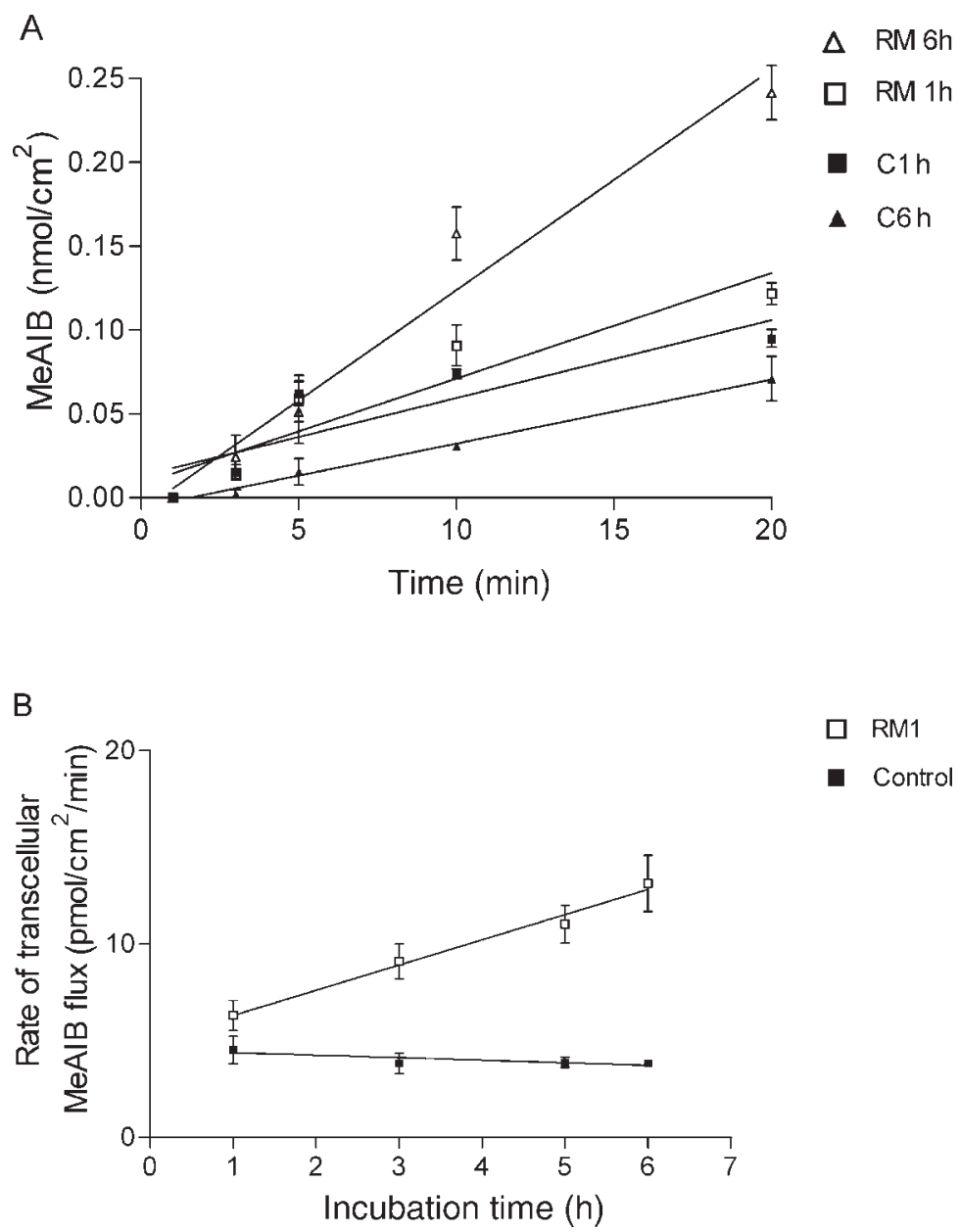

Figure 1 (A) Transcellular transport of MeAIB 1-20 min following the addition of $\left[{ }^{14} \mathrm{C}\right] \mathrm{MeAIB}$ to the apical side of BeWo monolayer after incubation of monolayers in control (C) or RM1 (RM) for $1 \mathrm{~h}\left(r^{2}\right.$ : C, 0.995; RM1, 0.989) and $6 \mathrm{~h}\left(r^{2}\right.$ : C, 0.993; RM1, 0.992). (B) Rate of MeAIB transcellular flux across monolayers of BeWo cells incubated in control medium or RM1 for $0,1,3,5$ or 6 h. Data points are means \pm S.E.M. $(n=6$ for each time-point and condition).

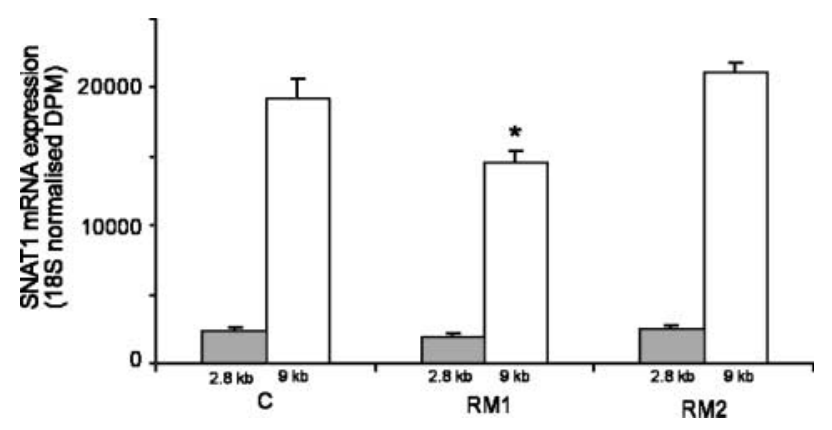

Figure 2 Mean \pm S.E.M. data $(n=9)$ summarised from Northern analysis of SNAT1 (2.8 kb (shaded bars) and $9 \mathrm{~kb}$ (open bars)) expression taken from each amino acid treatment as described in the the Materials and Methods section. Incubations lasted for $6 \mathrm{~h}$. Statistical analysis was carried out using one-way ANOVA with Tukey's multiple comparison (control (C) and RM1, $* P<0.01$; C and RM2, not significant; RM1 and RM2, $P<0.01$ ). $P$ values refer to significance of Tukey's multiple comparison tests between treatments. with control. SNAT2 mRNA levels continued to increase to 2.5 -fold control after $6 \mathrm{~h}$ of restriction (Fig. 3). The severity of amino acid restriction also affected SNAT2 mRNA expression. SNAT2 mRNA was significantly up-regulated further by a reduction in the concentration of essential amino acids as well as the removal of non-essential amino acids from the medium (RM2) for $6 \mathrm{~h}$ (Fig. 4).

\section{Effect of amino acid restriction on LAT2 mRNA}

LAT2 was expressed in BeWo cells, but changing amino acid levels under conditions that caused marked changes in SNAT2 expression had no effect on LAT2 mRNA levels (Fig. 5).

\section{Effect of amino acid restriction on SNAT2 protein localisation}

Incubation of BeWo cells with RM1 caused the relocalisation of SNAT2 transporters from the perinuclear (PN) region towards the plasma membrane compared with cells 


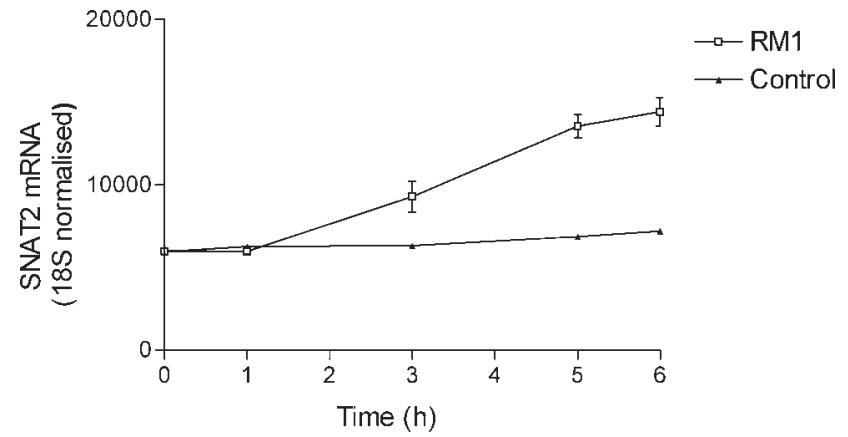

Figure 3 Data summarised from Northern analysis of SNAT2 mRNA expression (means \pm S.E.M., $n=12$ ) taken from each time-point and treatment as described in the Materials and Methods section. RM1 $(O)$ and control $(\mathbf{\Lambda})$. Statistical analysis was carried out using one-way ANOVA with Tukey's multiple comparison tests (control (C) and $1 \mathrm{~h}$, not significant; $C$ and $3 \mathrm{~h}, P<0.01 ; 1 \mathrm{~h}$ and $3 \mathrm{~h}, P<0.01$; $C$ and $5 \mathrm{~h}$, $P<0.001 ; 1 \mathrm{~h}$ and $5 \mathrm{~h}, P<0.001 ; \mathrm{C}$ and $6 \mathrm{~h}, P<0.001 ; 1 \mathrm{~h}$ and $6 \mathrm{~h}$, $P<0.001)$.

incubated in complete control medium. This relocalisation occurred within 30 min of incubation in RM1 (Fig. 6b) and throughout, whereas SNAT2 transporters remained in the PN region in time-matched control cells (Fig. 6a). This relocalisation reached a maximal point after about $2 \mathrm{~h}$ of incubation in RM1 (Fig. 6d) compared with time-matched controls (Fig. 6c). Anti-SNAT2 antibody specificity was determined using preincubation with antigenic peptide (Fig. 6e). Following extended periods of incubation in RM1 (4 h (Fig. 7b) and $6 \mathrm{~h}$ (Fig. 7d)) there was an increase in SNAT2 staining in the PN region as well as at the cell surface compared with time-matched controls (Fig. 7a and c), indicative of an increase in SNAT2 protein expression. Replenishing the amino acids in BeWo cells incubated in $\mathrm{RM} 1$ for $4 \mathrm{~h}$ by transfer into complete control medium for $2 \mathrm{~h}$ (Fig. 8a) caused SNAT2 transporters to be recycled away from the plasma membrane region and cells showed increased PN staining compared with time-matched cells incubated in RM1 (Fig. 8b).

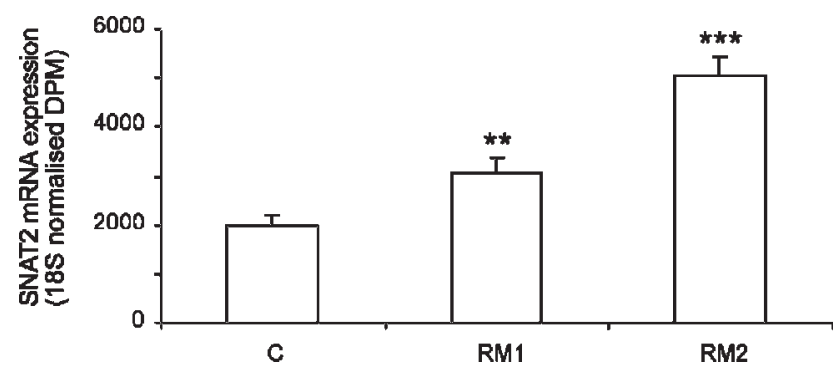

Figure 4 Data summarised from Northern analysis of SNAT2 mRNA (means \pm S.E.M., $n=9$ ) taken from each amino acid treatment as described in the Materials and Methods section. Incubations lasted for $6 \mathrm{~h}$. Statistical analysis was carried out using one-way ANOVA with Tukey's multiple comparison (control (C) and RM1, **P<0.01; $\mathrm{C}$ and RM2, $* * * P<0.001 ; \mathrm{RM} 1$ and RM2, $P<0.001)$.

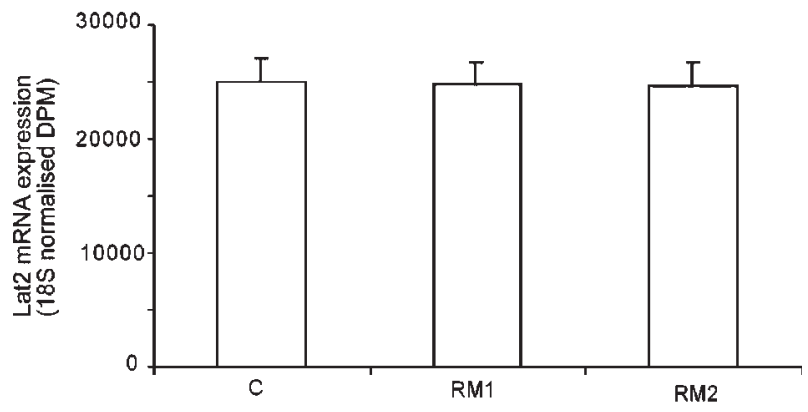

Figure 5 Data summarised from Northern analysis of LAT2 mRNA expression (means \pm S.E.M., $n=9$ ) taken from each amino acid treatment as described in the Materials and Methods section. Incubations lasted for $6 \mathrm{~h}$. Statistical analysis was carried out using one-way ANOVA (not significant).

\section{Effect of amino acid restriction on SNAT2 protein expression}

SNAT2 protein levels did not increase until $6 \mathrm{~h}$ after incubation in restriction medium RM1 (200 \pm 8.52 arbitrary expression units, $P<0.05, n=12)$ compared with timematched controls (175 \pm 7.6 arbitrary expression units, $n=12$ ) (Fig. 9).

\section{Discussion}

This study is the first to demonstrate that amino acid deprivation increases transfer of MeAIB across a placental cell layer and to investigate the alteration of expression at the molecular as well as the physiological level. It is important to remember that transfer also includes movement across the cell layer and efflux into the fetal circulation. Previous studies, using placental vesicles, identified a sodium-dependent AIB placental uptake system that was up-regulated by preincubation of placental fragments in amino aciddepleted medium (Smith et al. 1973, Smith \& Depper 1974, Enders et al. 1976, Ruzycki et al. 1978, Schlepphorst et al. 1980, Steel et al. 1982). However, these studies are limited, in that they do not determine the effect of deprivation on the net transfer of amino acid, or how the increased uptake is mediated. For example, they cannot tell whether the increase is as a result of changed localisation of transporters or of increased transcription or translation. Our data are particularly important given the central role of system A in amino acid transport in the placenta (Sibley et al. 1997, Cramer et al. 2002) and the fact that it is exquisitely sensitive to changes in fetal growth (or that changes in expression cause changes in fetal growth).

The TEER and $\left[{ }^{3} \mathrm{H}\right]$ mannitol data demonstrated that neither the integrity nor the permeability of the monolayers is changed by incubation in any of the restricted media. Furthermore, the amount of MeAIB transferred through the paracellular routes was never more than $10 \%$ total. Therefore responses to restricted amino acid availability were due to changes in specific transport mechanisms rather than a generalised change in the physical properties of the cell layer. 
(a)

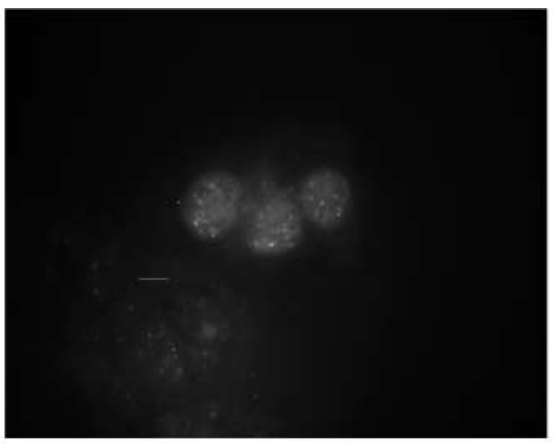

(c)

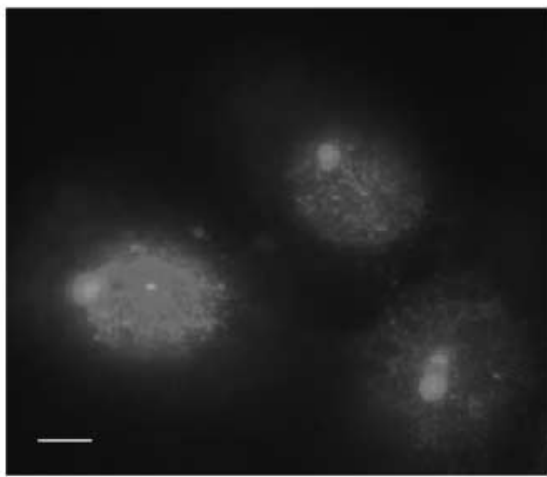

(e)

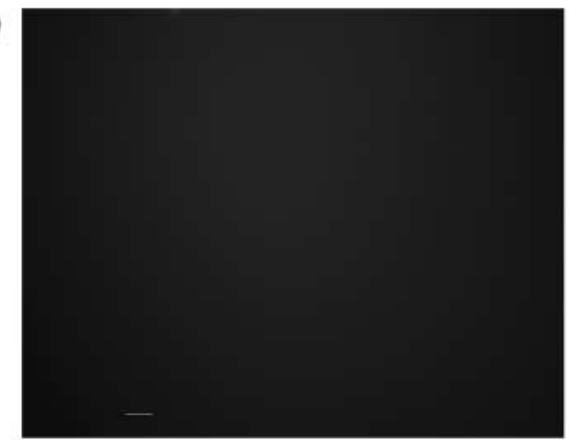

(b)

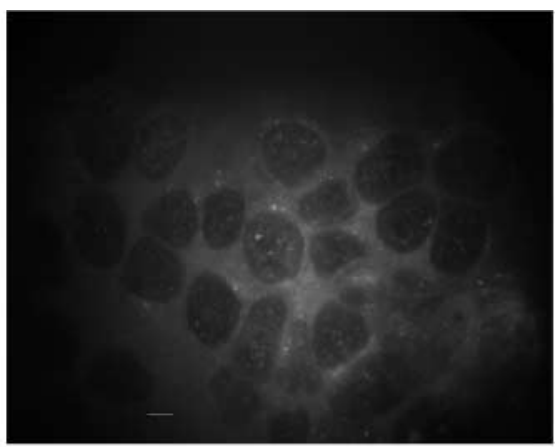

(d)

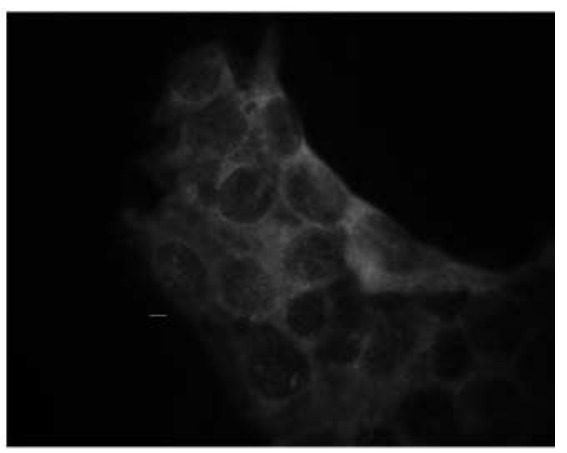

Figure 6 BeWo cells incubated in ( $a$ and c) control medium or (b and d) RM1 for (a and b) 30 min and (c and d) 2 h; stained with anti-SNAT2 antibody and FITC-anti-rabbit IgG antibody. (e) Antibody specificity was confirmed by preincubation with SNAT2 peptide prior to use in immunocytochemistry. Scale bars $=10 \mu \mathrm{m}$.

Our data have shown that uptake occurs in two phases. The first is a relocalisation of transporters from an intracellular pool to the cell surface. This corroborates and extends an earlier study in avian fibroblasts. Gazzola et al. (1972) demonstrated an increase in uptake which was not affected by cyclohexamide or actinomycin D, hence concluding that neither protein synthesis nor DNA transcription was required. Interestingly, Hundal's group (Hyde et al. 2001, 2002) have shown a similar response to insulin in myocytes and adipocytes. Using markers for subcellular fractions, they demonstrated that SNAT2 moves from an endosomal fraction to the surface in response to insulin treatment. It is tempting to conclude that there are common pathways and regulators involved in the responses to the different effectors, nutrient limitation and insulin treatment.
The second phase involves RNA and protein synthesis. It begins to become apparent after about $3 \mathrm{~h}$ in restricted medium but increases over the next $6 \mathrm{~h}$. It seems reasonable to conclude that this increase underpins the 'longterm regulation' identified by McGivan \& Pastor-Anglada (1994) in a very comprehensive review of system A regulation. They identify many factors and hormones that up-regulate system $\mathrm{A}$ uptake but do not show what the mechanism may be. Again, it is feasible that there are processes that underlie all these pathways.

It seems difficult to identify the changes in protein levels of system A in cells subjected to amino acid starvation, even when mRNA levels are increased. This was typified most recently in a study by Palii et al. (2004) identifying an amino acid regulator element in intron 1 of the SNAT2 gene. Here, the authors showed significant changes in 
(a)

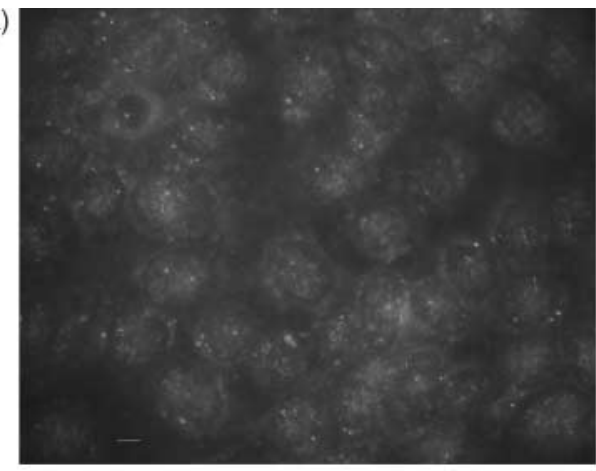

(c)

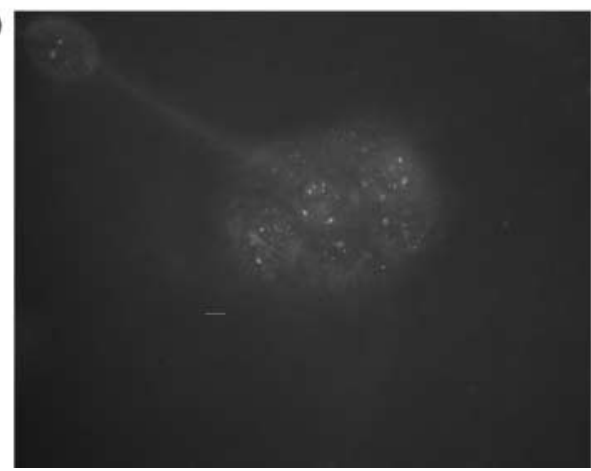

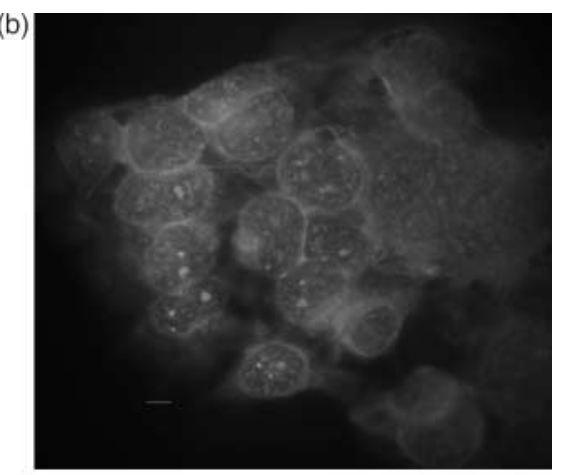

(d)

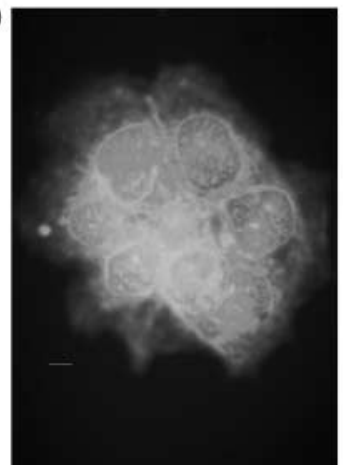

Figure 7 BeWo cells incubated in (a and c) control medium or (b and d) RM1 for (a and b) $4 \mathrm{~h}$ and (c and d) 6 h; stained with anti-SNAT2 antibody and FITC-anti-rabbit IgG antibody. Scale bar $=10 \mu \mathrm{m}$.

mRNA but not in protein. In contrast, we have shown small but significant increases in SNAT2 protein levels after 6 -h incubations in RM1. Why there should be a difference is not clear, but may relate to the severity of treatment. Additionally, the magnitude of the response of BeWo cells in contrast to HepG2 cells may be greater. Interestingly, we have noted similar differences in response to Fe deficiency in the two cell types ( $R$ Danzeisen, C Fosset \& H J McArdle, unpublished results). As might be expected in a physiological as opposed to a pathological response, replenishing the amino acid supply to the BeWo cells incubated in RM1 reduced SNAT2 staining at the cell surface, indicating the recycling of transporters back into the $\mathrm{PN}$ region.

In order to perform these experiments, we have grown BeWo cells on three different substrates: culture plates, cover slips and on permeable supports. This may result in alterations of the phenotype of the cells. We know that, for example, human chorionic gonadotrophin production by the cells is lower in cells on culture plates than on supports, so must consider that similar differences may be seen in the amino acid transfer mechanisms. However, we do not consider this likely. The mRNA and protein data all fit well with the transcellular transport of MeAIB in terms of magnitude and specificity. Our data are supported by the more limited studies carried out previously by other groups (Smith \& Depper 1974) and, taken together, make a comprehensive and comprehensible model for transplacental transport.
There are two transcripts for SNAT1, $9 \mathrm{~kb}$ and $2.5 \mathrm{~kb}$ (Hatanaka et al. 2001). In previous studies the most prominent mRNA species $(9 \mathrm{~kb})$ was up-regulated by the addition of cAMP (Hatanaka et al. 2001) and down-regulated by hypoxia (Nelson et al. 2003). No data on the expression of SNAT1 as a consequence of nutrient restriction have been published. In our study, 9 kb SNAT1 expression was downregulated by incubation in RM1, the opposite response to that of SNAT2. Surprisingly, following the restriction of essential amino acids (RM2) the expression levels of the $9 \mathrm{~kb}$ SNAT1 species are not reduced but increase compared with RM1 levels and return to control levels. Amino acid restriction does not appear to affect the expression of the $2.5 \mathrm{~kb}$ SNAT1 transcript. These results indicated that the two isoforms of system A may have differential sensitivity to essential amino acids. The tissue-specific expression of SNAT1 in the brain, heart and placenta (Wang et al. 2000) suggests that SNAT1 plays a very specific role in system A amino acid transport. Its role in the placenta remains to be elucidated.

Fong et al. (1990) demonstrated that the adaptive increase in amino acid transport system A does not reflect a generalised cell response, since the activity of other amino acid carriers is either unaffected or suppressed during periods of amino acid withdrawal. Our present studies on the system L transporter LAT2 expression supports this conclusion. The present studies also demonstrate that amino acid availability differentially regulates the expression of two system A amino acid transporters, 
(a)

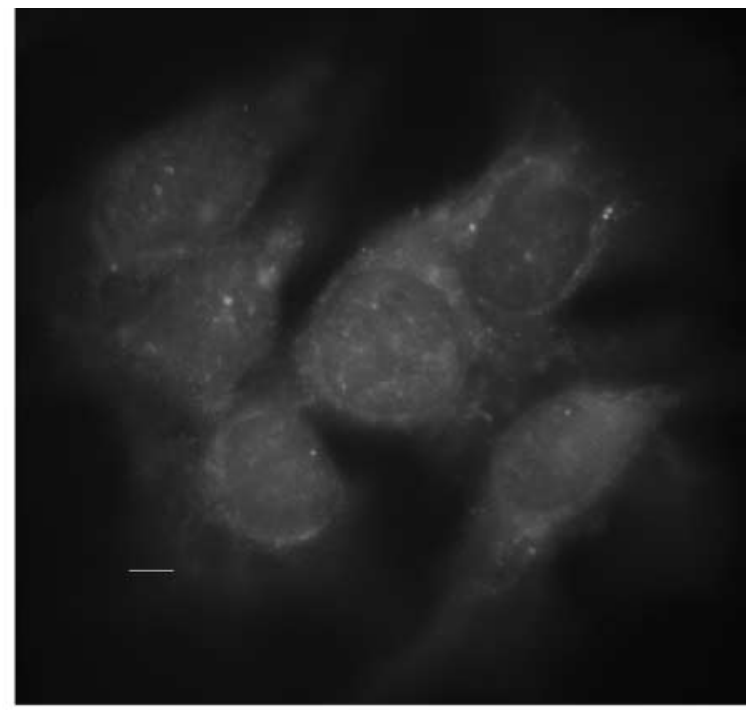

(b)

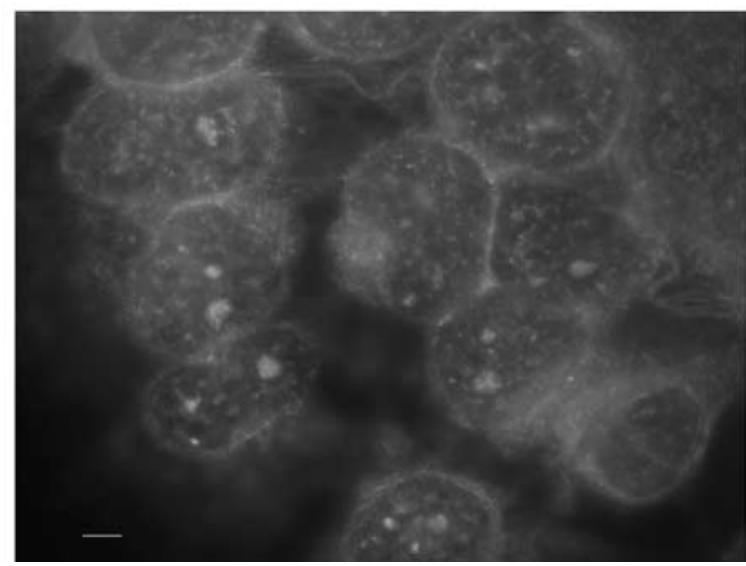

Figure 8 BeWo cells incubated in RM1 for $4 \mathrm{~h}$ then re-fed control medium for (a) $2 \mathrm{~h}$ or (b) remained in RM1 for a further $2 \mathrm{~h}$; stained with anti-SNAT2 antibody and FITC-anti-rabbit IgG antibody. Scale bar $=10 \mu \mathrm{m}$.

SNAT1 and SNAT2, but results in the overall increase in system A activity in the BeWo choriocarcinoma cell line. This is a potentially very valuable observation, since it may provide a hint as to how the two transporters work in concert to deliver essential nutrients from the mother to her developing fetus.

\section{Acknowledgements}

We thank Dr A L Schwartz (St Louis Children's Hospital, St Louis, MI, USA) for the supply of the BeWo cells and Dr P Sarmientos (PRIMM, Milan, Italy) for the production of the SNAT2 antibody. This work was funded by the Scottish Executive Environment and Rural Affairs Department flexible fund, the International Copper Association and Framework $\mathrm{V}$ QLK-1999-00337. The authors declare that there is no conflict of interest that would prejudice the impartiality of this scientific work.
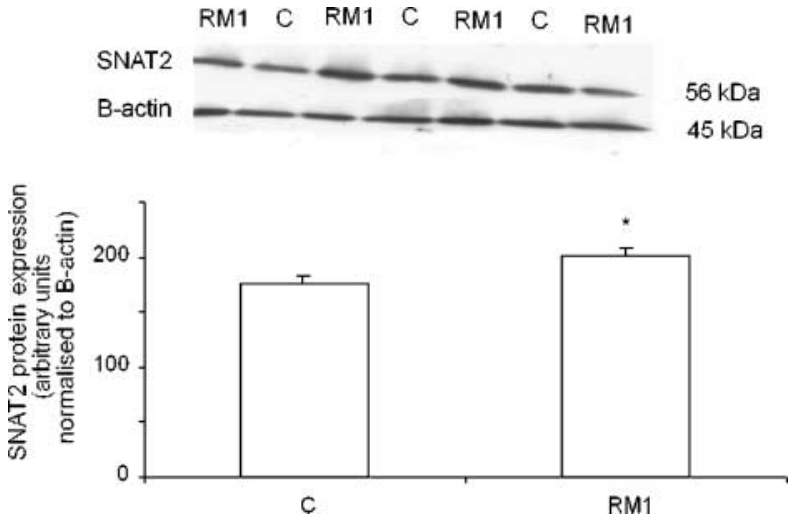

Figure 9 (Upper) Representative Western blot of human SNAT2 and corresponding $\beta$-actin Western blot (RM1: lanes 1, 3, 5 and 7; control lanes: 2, 4 and 6) following incubations for $6 \mathrm{~h}$. (Lower) Data summarised from Western analysis (means \pm S.E.M., $n=12$ ) taken from each amino acid treatment as described in the Materials and Methods section. Statistical analysis was carried out using the Student's $t$-test $(* P<0.05)$.

\section{References}

Bracy DS, Handlogten ME, Barber EF, Han HP \& Kilberg MS 1986 Cis-inhibition, trans-inhibition, and repression of hepatic amino acid transport mediated by system A. Substrate specificity and other properties. Journal of Biological Chemistry 261 1514-1520.

Carstensen MH \& Leichtweiss HP 1986 L-alanine carriers at maternal and fetal surfaces of the guinea pig placenta trophoblast. Gynecologic and Obstetric Investigation 22 172-185.

Cramer S, Beveridge M, Kilberg M \& Novak D 2002 Physiological importance of system-A mediated amino acid transport to rat fetal development. American Journal of Physiology: Cell Physiology 282 C153-C160.

Desforges M, Lacey HA, Glazier JD, Greenwood SL, Mynett KJ, Speake PF \& Sibley CP 2005 The SNAT4 isoform of the system A amino acid transporter is expressed in human placenta. American Journal of Physiology 290 C305-C312.

Enders RH, Judd RM, Donohue TM \& Smith CH 1976 Placental amino acid uptake. III. Transport systems for neutral amino acids. American Journal of Physiology 230 706-710.

Fong AD, Handlogten ME \& Kilberg MS 1990 Substrate-dependent adaptive regulation and trans-inhibition of system A-mediated amino acid transport. Studies using rat hepatome plasma membrane vesicles. Biochimica et Biophysica Acta 1022 $325-332$.

Franchi-Gazzola R, Visigalli R, Bussolati $O$, Dall'Asta V \& Gazzola GC 1999 Adaptive increase of amino acid transport system A requires ERK1/2 activation. Journal of Biological Chemistry $27428922-28928$.

Gambling L, Danzeisen R, Gair S, Lea R, Charania Z, Solanky N, Joory K, Srai SKS \& McArdle HJ 2001 The effect of iron deficiency on placental transfer of iron and expression of iron transport proteins in vivo and in vitro. Biochemical Journal 356 883-889.

Gazzola GC, Franchi R, Saibene V, Ronchi P \& Guidotti GG 1972 Regulation of amino acid transport in chick embryo heart cells. I. Adaptive system of mediation for neutral amino acids. Biochimica et Biophysica Acta 266 407-421.

Hatanaka T, Huang W, Wang H, Sugawara M, Prasad PD, Leibach FH \& Ganapathy V 2000 Primary structure, functional characteristics and tissue expression pattern of human SNAT2, a subtype of amino acid transport system A. Biochimica et Biophysica Acta $14671-6$. 
Hatanaka T, Huang W, Martindale RG \& Ganapathy V 2001 Differential influence of cAMP on the expression of the three subtypes (SNAT1, SNAT2 and ATA3) of the amino acid transport system A. FEBS Letters 505 317-320.

Hyde R, Christie GR, Litherland GJ, Hajduch E, Taylor PM \& Hundal HS 2001 Subcellular localization and adaptive up-regulation of the system A (SAT2) amino acid transporter in skeletalmuscle cells and adipocytes. Biochemical Journal 355 563-568.

Hyde R, Peyrollier K \& Hundal HS 2002 Insulin promotes the cell surface recruitment of the SAt2/SNAT2 system A amino acid transporter from an endosomal compartment in skeletal muscle cells. Journal of Biological Chemistry 277 13628-13634.

Jayanthi LD, Ramamoorthy S, Mahesh VB, Leibach FH \& Ganapathy V 1995 Substrate-specific regulation of the taurine transporter in human placental choriocarcinoma cells (JAR). Biochimica et Biophysica Acta 1235 351-360.

Karl PI 1995 Insulin-like growth factor-1 stimulates amino acid uptake by the cultured human placental trophoblast. Journal of Cell Physiology 165 83-88.

Lennon GG, Auffray C, Polymeropoulos M \& Soares MB 1996 The I.M.A.G.E. consortium, an integrated molecular analysis of genomes and their expression. Genomics 33 151-152.

Ling R, Bridges CC, Sugawara M, Fujita T, Leibach FH, Prasad PD \& Ganapathy V 2001 Involvement of transporter recruitment as well as gene expression in the substrate-induced adaptive regulation of amino acid transport system A. Biochimica et Biophysica Acta $151215-21$.

Liu F, Soares MJ \& Audus KL 1997 Permeability properties of monolayers of the human trophoblast cell line BeWo. American Journal of Physiology 273 C1596-C1604.

McDowell HE, Eyers PA \& Hundal HS 1998 Regulation of system A amino acid transport in L6 rat skeletal muscle cells by insulin, chemical and hyperthermic stress. FEBS Letters 441 15-19.

McGivan JD \& Pastor-Anglada M 1994 Regulatory and molecular aspects of mammalian amino acid transport. Biochemical Journal $299321-334$.

Moe AJ, Furesz TC \& Smith CH 1994 Functional characterization of L-alanine transport in a placental choriocarcinoma cell line (BeWo). Placenta 15 797-802.

Nelson DM, Smith SD, Furesz TC, Sadovsky Y, Ganapathy V, Parvin CA \& Smith CH 2003 Hypoxia reduces expression and function of system A amino acid transporters in cultured term human trophoblasts. American Journal of Physiology: Cell Physiology 284 C310-C315.

Novak D \& Matthews J 2003 Glutamate transport by Rcho-1 cells derived from rat placenta. Pediatric Research 53 1025-1029.

Okamoto $\mathrm{Y}$, Sakata $\mathrm{M}$, Ogura $\mathrm{K}$, Yamamoto T, Yamaguchi $\mathbf{M}$, Tasaka K, Kurachi H, Tsurudome M \& Murata Y 2002 Expression and regulation of $4 \mathrm{~F} 2 \mathrm{hc}$ and hLAT1 in human trophoblasts. American Journal of Physiology 282 C196-C204.

Palii SS, Chen H \& Kilberg MS 2004 Transcriptional control of the human sodium-coupled neutral amino acid transporter system A gene by amino acid availability is mediated by an intronic element. Journal of Biological Chemistry 279 3463-3471.

Pineda M, Fernandez E, Torrents D, Estevez R, Lopez C, Camps M, Lloberas J, Zorzano A \& Palacin M 1999 Identification of a membrane protein, LAT-2, that co-expresses with 4F2 heavy chain, an L-type amino acid transport activity with broad specificity for small and large zwitterionic amino acids. Journal of Biological Chemistry 274 19738-19744.

Ritchie JW \& Taylor PM 2001 Role of the system L permease LAT1 in amino acid iodothyronine transport in placenta. Biochemical Journal $356716-725$.

Ruiz-Montasell B, Gomez-Angelats M, Casado FJ, Felipe A, McGivan JD \& Pastor-Anglada M 1994 Evidence for a regulatory protein involved in the increased activity of system A for neutral amino acid transport in osmotically stressed mammalian cells. PNAS 91 9569-9573.
Ruzycki SM, Kelley LK \& Smith CH 1978 Placental amino acid uptake. IV. Transport of microvillous membrane vesicles. American Journal of Physiology 234 C27-C35.

Schlepphorst E, Kelley LK \& Smith CH 1980 Placental amino acid uptake. V. Relationship to placental maturation in the rat. American Journal of Obstetics and Gynecology 137 499-504.

Schneider H, Proegler M, Sodha R \& Dancis J 1987 Asymmetrical transfer of alpha-aminoisobutyric acid (AIB), leucine and lysine across the in vitro perfused human placenta. Placenta 8 141-151.

Sibley C, Glazier J \& D'Souza S 1997 Placental transporter activity and expression in relation to fetal growth. Experimental Physiology 82 389-402.

Smith CH \& Depper R 1974 Placental amino acid uptake. II. Tissue preincubation, fluid distribution and mechanisms of regulation. Pediatric Research 8 697-703.

Smith CH, Adcock EW 3rd, Teasdale F, Meschia G \& Battaglia FC 1973 Placental amino acid uptake: tissue preparation, kinetics, and preincubation effect. American Journal of Physiology 224 558-564.

Steel RB, Smith CH \& Kelley LK 1982 Placental amino acid uptake. VI. Regulation by intracellular substrate. American Journal of Physiology 243 C46-C51.

Sugawara M, Nakanish T, Fei YJ, Huang W, Ganapathy ME, Leibach FH \& Ganapathy V 2000a Cloning of an amino acid transporter with functional characteristics and tissue expression pattern identical to that of system A. Journal of Biological Chemistry 275 16473-16477.

Sugawara M, Nakanishi T, Fei YJ, Martindale RG, Ganapathy ME, Leibach FH \& Ganapathy V 2000b Structure and function of ATA3, a new subtype of amino acid transport system A, primarily expressed in the liver and skeletal muscle. Biochimica et Biophysica Acta 1509 7-13.

Takahashi T, Utoguchi N, Takara A, Yamamoto N, Nakanishi T, Tanaka T, Audus KL \& Watanabe Y 2001 Carrier-mediated transport of folic acid in BeWo cell monolayers as a model of the human trophoblast. Placenta 22 863-869.

Tarnuzzer RW, Campa MJ, Qian NX, Engelsberg E \& Kilberg MS 1990 Expression of the mammalian system A amino acid transporter in Xenopus oocytes. Journal of Biological Chemistry 265 13914-13917.

Utoguchi N \& Audus KL 2000 Carrier-mediated transport of valproic acid in BeWo cells, a human trophoblast cell line. International Journal of Pharmacology 195 115-124.

Vardhana PA \& Illsley NP 2002 Transepithelial glucose transport and metabolism in BeWo choriocarcinoma cells. Placenta 23 653-660.

Wang H, Huang W, Sugawara M, Devoe LD, Leibach FH, Prasad PD \& Ganapathy V 2000 Cloning and functional expression of SNAT1, a subtype of amino acid transporter A, from human placenta. Biochemical and Biophysical Research Communications $2731175-1179$.

Way BA, Furesz TC, Schwarz JK, Moe AJ \& Smith CH 1998 Sodiumindependent lysine uptake by the BeWo choriocarcinoma cell line. Placenta 19 323-328.

Wheeler CP \& Yudilevich DL 1989 Lysine and alanine transport in the perfused guinea-pig placenta. Biochimica et Biophysica Acta $978257-266$.

Wice B, Menton D, Geuze H \& Schwartz AL 1990 Modulators of cyclic AMP metabolism induce syncytiotrophoblast formation in vitro. Experiments in Cell Research 186 306-316.

Yao D, Mackenzie B, Ming H, Varoqui H, Zhu H, Hediger MA \& Erickson JD 2000 A novel system A isoform mediating Na+/neutral amino acid cotransport. Journal of Biological Chemistry 275 22790-22797.

Received 18 May 2005

First decision 23 June 2005

Revised manuscript received 15 December 2005

Accepted 9 February 2006 